\title{
Optimal Planning and Investment Benefit Analysis of Shared Energy Storage for Electricity Retailers
}

\author{
Jichun Liu', Xue Chen', Yue Xiang' ${ }^{1 *}$, Da Huo², Junyong Liu ${ }^{1}$ \\ 1 College of Electrical Engineering, Sichuan University, Chengdu 610065, China. \\ 2 School of Engineering, Newcastle University, Newcastle, NE1 7RU UK.
}

\begin{abstract}
With the rapid development of energy storage (ES) technology, it has gradually become a vital facility to cope with the intermittent renewable generation and reduce the users' electricity purchase cost. However, the limited application of the ES has suffered from its high capital cost. This paper proposes an approach of optimal planning the shared energy storage based on cost-benefit analysis to minimize the electricity procurement cost of electricity retailers. First, the multi-time scale electricity purchase model is established. Then the retailers are screened and classified based on the proposed matching degree function to select the collective of retailers, which maximizes the profits of planning the shared ES. The life cycle cost model and the equivalent cycle life method are used to evaluate the benefit of investing the shared ES. The benefit distribution among the collective is conducted based on the contribution degree of each retailer. In the case study, the optimization results of the shared ES for high-matching and low-matching groups are compared in detail. The simulation results illustrate that the costs of electricity retailers are reduced by $8.83 \%$ and $8.03 \%$ respectively for the two groups of retailers. The results verify that ES can effectively reduce the cost of retailers, and high matching degree can be used as the selection criterion to obtain a greater benefit of the shared ES.
\end{abstract}

Key Words: Electricity retailer, Shared energy storage, Matching degree, Life cycle cost, Investment evaluation

\section{NOMENCLATURE}

\begin{tabular}{|c|c|}
\hline$C_{\mathrm{d}}$ & The electricity purchase cost of the day-ahead market. \\
\hline$C_{\mathrm{d}}$ & The electricity purchase cost of the real-time market. \\
\hline$c_{\mathrm{pu}}^{\mathrm{t}} / c_{\mathrm{pl}}^{\mathrm{t}}$ & Up-regulated/down-regulated unit price at time interval $t$. \\
\hline$P_{\mathrm{pu}}^{\mathrm{t}} / P_{\mathrm{pl}}^{\mathrm{t}}$ & Up-regulated/down-regulated electricity at time interval $t$. \\
\hline$\varepsilon$ & $\begin{array}{l}\text { The average daily matching degree between electricity retailer } i \\
\text { and } j \text {. }\end{array}$ \\
\hline$C_{\text {ess }}$ & Investment cost of ES. \\
\hline$m$ & The number of electricity retailers. \\
\hline$P_{t \mathrm{~L}}$ & $\begin{array}{l}\text { Actual load demand of the electricity retailer at time interval } \\
t \text {. }\end{array}$ \\
\hline
\end{tabular}




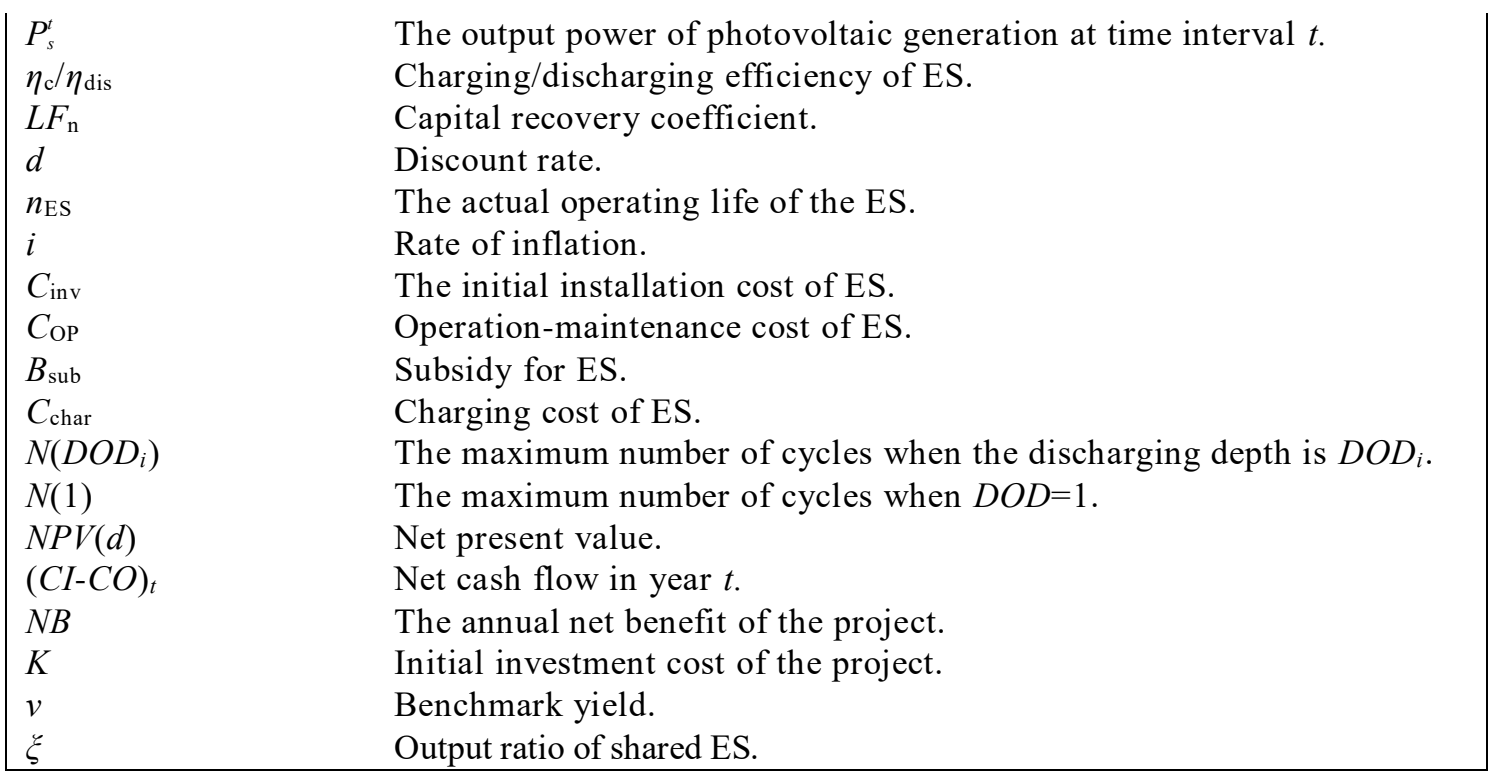

\section{Introduction}

Nowadays, the configured capacity of new energy resources, such as solar and wind energy, has been increasing dramatically because of the government subsidy and drop in the capital cost. However, the new energy resources may create several serious operational issues, such as over-voltage and continuous fluctuations of the electricity price[1-3]. Moreover, for users, the fluctuation of electricity prices and the uncertainty of renewable energy resources' output power will influence their economic benefits. The countermeasures to address these negative effects of new energy resources mainly contain the active demand response and the installation of ES[4-7]. ES has a dual characteristic of operating as the power supply or load, which can store redundant energy during the valley periods and release the stored energy back to the grid during the peak periods. Under the mechanism of time-of-use electricity price, it can not only improve the power quality but also reduce the electricity purchase cost. The instinct feature of ES makes it an ideal candidate to solve the aforementioned operational issues, therefore, attracts substaintial investment in ES facilities [8].

The key to ES development is how to invest and operate ES according to the specific needs of users. Previous studies on ES have verified that it can provide various services for investors with different objectives. The power grid benefits from using the ES by delaying the investment of distribution network equipment and improving the power quality through peak shaving; as for 
industrial and commercial users, ES can be employed as a backup power supply to reduce the economic loss caused by power failure [9-11]. Besides, most existing researches concentrate on the capacity allocation of ES from the technical perspective or carrying out a separate cost-benefit analysis of ES. Ref. [12] defined an ES cost model that considered long-term, medium-term and short-term ES applications. In [13], a cost-efficient application of different battery ES technologies in microgrids considering load uncertainty was introduced, the purpose was to minimize total cost and maximize the reliability index considering the uncertainty of load demand as well as the output power of the wind and solar generators. Aiming at minimizing the total cost of the system, a capacity configuration model of ES by combining wind energy, solar energy, and gravity energy were established in [14], to optimize the capacity of the on-grid wind-photovoltaic-storage hybrid power system.

However, due to the high installation cost, the application of ES is still limited and economically unattractive [15]. The situation is changing as the sharing economy develops rapidly. As known, sharing economy is based on the concept of sharing under-utilized resources and services (such as transportation and housing), thereby reducing costs and extracting value[16]. Shared ES means that multiple users jointly invest and operate new ES equipment or cooperatively operates the existing ES equipment[17]. A sharing economy-based model may increase the profitability of operating a battery storage system compared to the single-use case business model[18]. In [19], the operating costs of two producers were minimized by the optimal Peer-to-Peer (P2P) energy sharing of grid-connected consumers, in which the life-cycle cost and break-even analyses of shared ES were conducted for the prosumers of the P2P.

In earlier publications, the shared ES is mainly used to promote the response of household energy demand and promote PV permeability in the low-voltage distribution network, the objective is typically to reduce users' energy costs and alleviate network operation problems [20-22]. By analyzing the actual data, it was confirmed that shared batteries of $2-3 \mathrm{~kW} \cdot \mathrm{h}$, per apartment, could increase solar self-consumption by up to $19 \%$ and building self-sufficiency by up to $12 \%$ [23]. Paper [24] proposes a multi-stage stochastic programming approach for energy management and optimal storage sizing of a shared community. Some studies on shared ES focused on cost-benefit analysis. Literature [25] analyzed and quantified the economic and 
operational benefits of shared ES for neighboring producers in a dynamic pricing environment, the economic benefits of shared ES were produced through its use as a key tool in the demand response process. In [26], the shared ES in residential microgrids helped households store excess renewable energy, the home appliances and shared ES were jointly scheduled based on reputation, while the reduced energy cost for each household was quantified. However, the above studies have only considered cost-benefit analysis on the shared ES.

Additionally, previous studies ignored the influence of the load curve morphology of multiple users on the economic benefits of shared ES. They only analyzed the shared ES application for fixed users, while ignored the potential for further economic saving by employing the shared ES on users with similar behaviors. In this paper, we focus on the optimal planning of shared ES for electricity retailers by cost-benefit analysis considering the similarity between users, quantified by matching degree. Using matching degree to screen retailers maximizes the overall economic profits, and benefits the coordinate operations of the collective of retailers in using the shared ES.

Compared to the existing work on shared ES, our study innovates in terms of the following three key contributions: i) An optimal planning and cost-benefit analysis model of shared ES for electricity retailers is established, which innovatively improves their economic benefits; ii) The matching degree model and two methods of selecting retailers are proposed, by which the greater economic benefits and management of the shared ES are realized with the new method; iii) The models of output ratio of the shared ES and the contribution degree of each electricity retailer in the collective are established to realize the simpler and fair allocation of benefits.

The remainder of the paper is organized as follows. Section 2 establishes the electricity purchase model of retailers, section 3 introduces the necessity of selecting electricity retailers and sets up the matching degree calculation model. The optimal planning model of the shared ES is presented in section 4. The cost-benefit analysis of ES is carried out in section 5, and the benefit distribution method of shared ES based on the collective contribution of the retailers is proposed. In section 6 , the case study is analyzed. Finally, section 7 summarizes the study.

\section{Electricity Purchase Model of Retailers}

The electricity procurement process of the electricity retailer is composed of three stages as follows. Firstly, electricity is purchased in the medium-long term market, aiming to meet the 
demand of most customers. Then, the residual electricity demand is satisfied by centralized bidding in the day-ahead market. Meanwhile, the shared ES can be accordingly charged or discharged in response to the electricity price fluctuation, and to eliminate a part of the deviation between the predicted and actual load. The remaining electricity forecast errors need to be addressed by importing electricity from the real-time market. Consequently, the electricity retailer meets the demand of all consumers it represents[27].

In this paper, the shared ES is only considered to participate in the day-ahead market and real-time market, the electricity purchase model of medium-long term market is not established.

\subsection{Electricity Purchase in the Day-ahead Market}

Electricity transaction in the day-ahead market adopts the centralized bidding mode and unified clearing. Statistics show that the clearing price in the day-ahead market is approximately linearly correlated with the load level of the system [28-29], so the electricity purchase cost of the day-ahead market can be estimated by

$$
\begin{aligned}
& C_{\mathrm{d}}=\sum_{t=0}^{T-1} c_{\mathrm{d}}^{t} P_{\mathrm{d}}^{t} \\
& c_{\mathrm{d}}^{t}=A P_{\mathrm{d}}^{t}+B
\end{aligned}
$$

where $P_{d}^{t}$ and $c_{d}^{t}$ are the electricity purchased and price at time $t$ in the day-ahead market; $A$ and $B$ are the quote coefficients. For the sake of simplicity, we assume that all declared electricity can be traded.

\subsection{Electricity Purchase in the Real-time Market}

After the transaction in the day-ahead market, the remaining unsatisfied electricity demand is met by operating the ES and purchasing electricity in the real-time market.

When the electricity purchased by the electricity retailer is less than its user's load, it needs to purchase the up-regulated power in the real-time market, otherwise, it needs to purchase the down-regulated power.

The electricity procurement of the real-time market can be calculated as

$$
C_{\mathrm{T}}=\sum_{t=0}^{T-1}\left(c_{\mathrm{pu}}^{t} P_{\mathrm{pu}}^{t}+c_{\mathrm{pl}}^{t} P_{\mathrm{pl}}^{t}\right)
$$


The total purchased electricity of the electricity retailer at time $t$ can be identified with

$$
P_{\mathrm{buy}}^{t}=P_{\mathrm{d}}^{t}+P_{\mathrm{pu}}^{t}-P_{\mathrm{pl}}^{t}
$$

Finally, the total electricity purchase cost can be expressed as

$$
C_{\text {buy }}=C_{\mathrm{d}}+C_{\mathrm{T}}
$$

\subsection{Photovoltaic Uncertain Generation Model}

Investment in ES is driven by the growing popularity of renewable energy. The uncertainty of the solar photovoltaic generation is modelled in this section in order to capture the effect of stochastic renewable energy on system operations. In this paper, electricity retailers are equipped with photovoltaic power generation devices. The output power of photovoltaic generation is another electricity source of retailers, except for the power from the power market.

According to the historical data of regional illumination, the solar illumination intensity, $s$, approximately follows the Weibull distribution in a certain period [30]. The relationship between the output power of photovoltaic generation and the sunlight irradiation intensity can be expressed by the following formula,

$$
P_{\mathrm{s}}^{t}= \begin{cases}P_{\mathrm{sn}}\left(\frac{s_{t}}{s_{\mathrm{n}}}\right), & 0 \leq s_{t} \leq s_{\mathrm{n}} \\ P_{\mathrm{sn}} & s_{t} \geq s_{\mathrm{n}}\end{cases}
$$

where $P_{\mathrm{sn}}$ is the rated output power of photovoltaic generation; $s_{\mathrm{n}}$ is the illumination intensity at rated output power; $s_{t}$ is the illumination intensity at time interval $t$.

\section{Matching Degree Calculation and User Screening}

The shared ES's optimal configuration and its charging and discharging operations are closely related by the fluctuation of user's load curve. Correspondingly, the economic benefit of shared ES can be affected by the fluctuation trend of each user's load curve within the collective. The economic profit of using shared ES can either be benefited or deducted depending on the degree of similarity between users' load curves. Therefore, we define the matching degree to quantify the similarity between two load curves, which is the average value of the similarity between two curves at each time interval of one day. 
The changing trend of the load curve can be estimated by its slope changing. Slope correlation is an analytic method based on the slope of a curve. We can obtain the matching degree by calculating the slope correlation between two curves, of which the value is between 0 and 1 . Taking electricity retailer $i$ and $j$ as examples, the correlation function between their load curves at each time interval, $\psi(t)$, can be calculated by

$$
\begin{gathered}
\psi(t)=\frac{1}{1+\left|\frac{1}{\tau_{i}} \frac{\Delta P_{\mathrm{L}}^{i}(t)}{\Delta t}-\frac{1}{\tau_{j}} \frac{\Delta P_{\mathrm{L}}^{j}(t)}{\Delta t}\right|} \\
\Delta P_{\mathrm{L}}^{i}(t)=P_{\mathrm{L}}^{i}(t+1)-P_{\mathrm{L}}^{i}(t) \\
\Delta P_{\mathrm{L}}^{j}(t)=P_{\mathrm{L}}^{j}(t+1)-P_{\mathrm{L}}^{j}(t) \\
\tau_{i}=\sqrt{\frac{1}{T} \sum_{t=1}^{T}\left[P_{\mathrm{L}}^{i}(t)-P_{\mathrm{Lav}}^{i}(t)\right]^{2}} \\
P_{\mathrm{Lav}}^{i}(t)=\frac{1}{T} \sum_{T}^{t=1} P_{\mathrm{L}}^{i}(t) \\
\tau_{j}=\sqrt{\frac{1}{T} \sum_{t=1}^{T}\left[P_{\mathrm{L}}^{j}(t)-P_{\mathrm{Lav}}^{j}(t)\right]^{2}} \\
P_{\mathrm{Lav}}^{j}(t)=\frac{1}{T} \sum_{T}^{t=1} P_{\mathrm{L}}^{j}(t)
\end{gathered}
$$

where $\tau_{i}$ and $\tau_{j}$ restrict the load standard deviation of electricity retailer $i$ and $j$ respectively.

After simplification, the correlation at time interval $t$ can be calculated as

$$
\psi(\mathrm{t})=\frac{1}{1+\left|\frac{\Delta P_{\mathrm{L}}^{i}(t)}{\tau_{i}}-\frac{\Delta P_{\mathrm{L}}^{j}(t)}{\tau_{j}}\right|}
$$

Finally, the average matching degree between electricity retailer $i$ and electricity retailer $j$ over the time horizon $T$ can be calculated as:

$$
\varepsilon=\frac{1}{T} \sum_{t=1}^{T} \psi(t)
$$




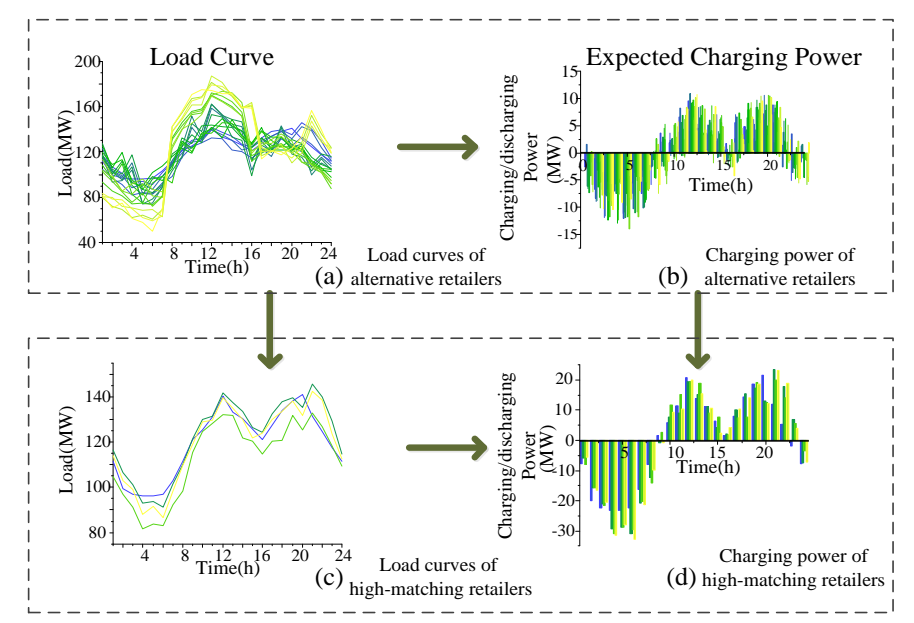

Fig.1.Load curves and charging power of electricity retailers

The load curves and charging power of alternative electricity retailers and high-matching retailers are depicted in Fig. 1. As seen, Fig. 1 (a) shows the load curves of different retailers in order for screening, Fig. 1 (b) shows the charging and discharging demand of each retailer. The retailers with similar variations of load curves as shown in Fig. 1 (c) are selected when the screening is carried out based on high matching degree. Correspondingly, their charging and discharging demands are also similar, as depicted in Fig. 1 (d). A higher matching degree indicates that the required charging and discharging power of the shared ES will be greater within a specific time interval. Moreover, as the users' charging periods are relatively concentrated in a day, the frequency of charging the ES can be reduced for a collective of retailers with high matching degree. Its disadvantage is that when the collective is composed of retailers with similar load curves, the overall difference between the load peak and valley will be more distinct, which may limit the time-shifting capacity of the shared ES on load.

While the low matching degree can increase the charging-discharging frequency of shared ES and improve its utilization rate. Nevertheless, its disadvantage is that frequent charging-discharging will shorten the lifetime of ES, thus affecting its economic benefits. In the case study, we will select two shared ES retailer groups through the aforementioned screening methods. And we will compare and analyze the economic benefits of shared ES in the two cases. Moreover, the optimization results of ES configured separately and shared ES are also compared in detail.

Since the daily load of the consumers is random and volatile, the average annual load is selected 
for the screening practice.

\section{Optimal Planning of Shared ES for Retailers}

As mentioned in section 1, there are two alternative choices for the shared ES application. For the purpose of simplicity, we choose the second mode for detailed analysis, that is, retailers jointly install an ES and operate it cooperatively.

As known, electricity retailers purchase electricity in the medium-long term market, day-ahead market and real-time market respectively [31]. Meanwhile, their procurement cost of electricity can be reduced through arbitraging the shared ES in the day-ahead market and real-time market. Each electricity retailer eventually satisfies the electricity demand of its customers. Aiming at minimizing their electricity purchase cost, the shared ES' $\mathrm{s}$ configuration parameters together with its charging-discharging process over the planning horizon are optimized, as illustrated in Fig. 2.

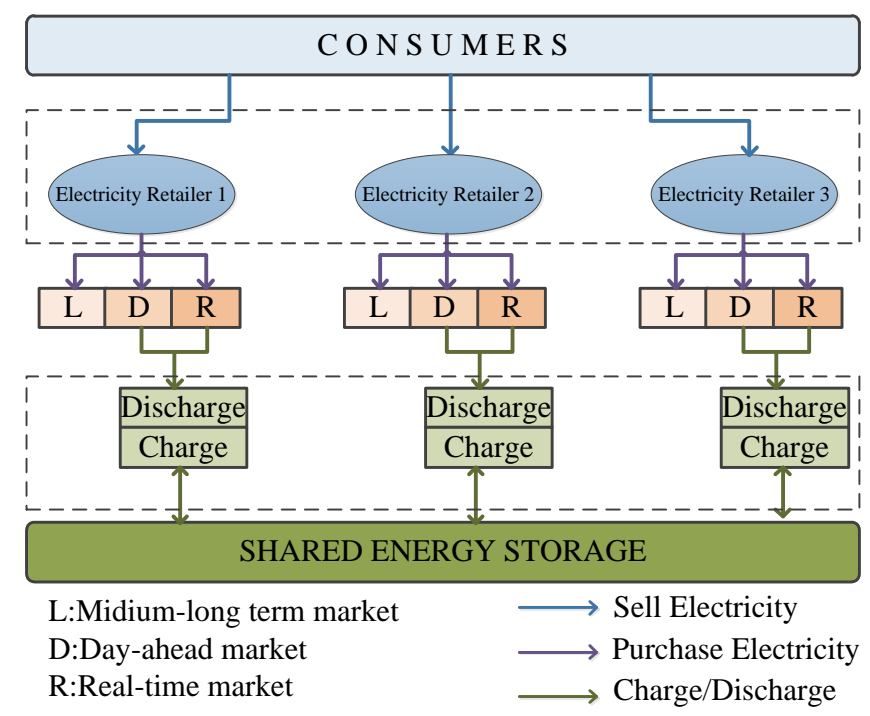

Fig.2. Shared energy storage system among multiple electricity retailers

\subsection{Objectives of the Optimal Planning Model}

The objective of the optimal planning problem is to minimize the total costs of the collective, expressing as the sum of energy costs and the life cycle cost of the shared ES. The objective function can be formulated as

$$
\min F=\min \left(\sum_{i=1}^{m}\left(C_{\text {buy }}^{i}\right)+C_{\text {ess }}\right)
$$

where $C_{\text {buy }}^{i}$ is the electricity purchase cost of retailer $i$.

The life cycle cost model of shared ES is established in section V. 


\subsection{Constraints of the Optimal Planning Model}

The constraints for the optimization problem contain the ES system constraints, electricity cost constraint and balancing constraint between electricity supply and demand. They are explained as follows:

1) Constraints of the ES System

$$
\begin{gathered}
S O C_{t}=\frac{S_{t}}{E_{\mathrm{rate}}} \\
S O C_{\min } \leq S O C_{t} \leq S O C_{\max } \\
P_{\mathrm{c}}^{t}=\sum_{i=1}^{m} P_{\mathrm{c}, i}^{t} \\
P_{\mathrm{dis}}^{t}=\sum_{i=1}^{m} P_{\mathrm{dis}, i}^{t} \\
P_{\mathrm{c}, i}^{t} P_{\mathrm{dis}, i}^{t}=0 \\
-P_{\mathrm{c}, \text { max }} \leq P_{t} \leq P_{\mathrm{dis}, \max } \\
P_{\mathrm{c}}^{t} P_{\mathrm{dis}}^{t}=0 \\
S_{t}=S_{t-1}+P_{\mathrm{c}}^{t-1} \eta_{\mathrm{c}} \Delta \mathrm{t}-\frac{P_{\mathrm{dis}}^{t-1} \Delta \mathrm{t}}{\eta_{\mathrm{dis}}} \\
S_{1}=S_{T}
\end{gathered}
$$

where $S O C_{\min }$ and $S O C_{\max }$ restrict the minimum and maximum residual energy level; $\boldsymbol{E}_{\text {rate }}$ is the rated capacity of ES; $S_{t}$ is the remaining electricity in the shared ES at time $t ; P_{\mathrm{c}}^{t}$ and $P_{\mathrm{dis}}^{t}$ denote the total charging and discharging power at time $t ; P_{\mathrm{c}, i}^{t}$ and $P_{\mathrm{dis}, i}^{t}$ are the charging and discharging power of the electricity retailer $i$ using the shared ES at time $t$.

The remaining electricity of the ES at the first and final time periods of the optimization time horizon are assumed to have the same quantity.

2) The constraint of the electricity cost

$$
C_{\text {buy }}^{i}<C_{\text {buy } 0}^{i} \quad(i=1,2, \ldots m)
$$

where $C_{\text {buy } 0}^{i}$ is the electricity purchase cost of retailer $i$ without the application of the shared ES. 


$$
P_{\mathrm{buy}}^{t^{\prime}}+P_{\mathrm{s}}^{t}+P_{\mathrm{pu}}^{t}-P_{\mathrm{pl}}^{t}=P_{1}^{t}
$$

\section{Investment Benefit Analysis of Shared ES for Retailers}

\subsection{Life Cycle Cost Model of Shared ES}

Life cycle cost is the sum of total costs which have occurred and are likely to occur during the lifetime of the analyzed system. Specifically, it is composed of the initial investment cost, operation-maintenance cost, auxiliary facility cost, replacement cost, scrap cost, and residual value. As known, the initial investment cost and operation-maintenance cost account for the largest proportion, which is explicitly considered in this paper.

\section{1) Initial Installation Cost}

The initial installation cost refers to the fixed capital invested at the initial stage of construction. The initial investment cost of the shared ES is determined by the rated power and capacity [32], which can be quantified by:

$$
\begin{gathered}
C_{\mathrm{inv}}=L F_{\mathrm{n}}\left(c_{\text {pinv }} P_{\text {max }}+c_{\text {einv }} E_{\text {rate }}\right) \\
L F_{\mathrm{n}}=\frac{d(1+d)^{n_{\mathrm{ES}}}}{(1+d)^{n_{\mathrm{ES}}}-1}
\end{gathered}
$$

where $c_{\text {pinv }}$ and $c_{\text {einv }}$ restrict the unit power and capacity cost of ES; $P_{\max }$ is the maximal charging-discharging power.

\section{2) Operation-maintenance Cost}

Operation-maintenance cost refers to the funds dynamically spent to ensure the normal ES system operations over its lifetime, which can be calculated as

$$
C_{\mathrm{OP}}=L F_{\mathrm{n}} \sum_{i=1}^{n_{\mathrm{ES}}} C_{\mathrm{op}, i} P_{\max }\left(\frac{1+i}{1+d}\right)^{i}
$$

where $C_{\mathrm{op}, i}$ denote the operating-maintenance cost per unit power in the year $i$.

\section{3) Subsidy for ES}

At present, the government subsidy mechanism for the ES projects mainly includes the subsidy on ES's charging-discharging electricity and the subsidy for a certain proportion of the initial investment cost. The first subsidy scheme is adopted in this paper, which can be formulated as 


$$
B_{\text {sub }}=e_{\text {sub }} \sum_{t=0}^{T-1} Q_{\mathrm{c}}^{t}
$$

where $e_{\text {sub }}$ is the per-unit electricity government subsidy and $Q_{\mathrm{c}}^{t}$ is the charging-discharging electricity at period $t$.

4) Charging Cost

As mentioned before, the shared ES mainly participates in the day-ahead market, so the charging cost is determined by the charging electricity and clearing price, which can be expressed as

$$
C_{\text {char }}=\sum_{t=0}^{T-1} Q_{c}^{t} p_{\mathrm{d}}^{t}
$$

In summary, the cost-benefit of the investment on the shared ES can be calculated by summing the initial investment cost, operation-maintenance cost, charging cost over the ES life cycle minus the subsidy as

$$
C_{\text {ess }}=C_{\mathrm{inv}}+C_{\mathrm{OP}}+C_{\mathrm{char}}-B_{\mathrm{sub}}
$$

It is assumed that the photovoltaic facilities of electricity retailers already exist before the installation of shared ES, so its planning and investment are not considered in this paper.

\subsection{Calculation of Operating Life of ES}

The actual operating life of the ES system is shorter compared with the expected lifetime, reflected by the capacity fading over-usage [33-34]. The factors that affect the actual operating life include temperature, peak current, discharging depth, discharging times, etc. Among them, discharging depth is the most critical factor that impacts the ES lifetime. Generally, the larger the discharging depth is, the greater the impact on ES operating life will be. The difference between different levels of Depth of Discharges (DoD) a and b can be expressed by their state of charges as

$$
D O D_{a b}=\left|S O C_{a}-S O C_{b}\right|
$$

The equivalent cycle coefficient of the ES is defined as ${ }^{\alpha}$, which can be expressed as

$$
\alpha\left(D O D_{i}\right)=\frac{N(1)}{N\left(D O D_{i}\right)}
$$

Then the rain flow counting method is used to count and extract each actual cycle period [35]. With a quantity of $\mathrm{n}$, corresponding to $D O D_{1} \cdots, D O D_{n}$, the number of equivalent 
cycles over a certain analyzed period can be expressed as

$$
N^{\prime}=\sum_{i=1}^{n} \alpha\left(D O D_{i}\right)
$$

The life loss coefficient can be derived in terms of the equivalent cycle number as

$$
\beta=\frac{N}{N(1)}
$$

For example, when the analyzed period is chosen as one day, the actual operating life can be calculated as

$$
n_{\mathrm{ES}}=\frac{1}{\beta}
$$

\subsection{Calculation of the Investment Payback Period of Shared ES}

The dynamic investment payback period is calculated after the net cash flow of the invested project converting into the present value, based on the benchmark payback rate [36]. It complements the defect that the static investment payback period neglects the time value of capital, and is also aligned with the real-world application.

The dynamic investment payback period is set as $T_{p}$, which can be calculated as

$$
\begin{gathered}
\sum_{t=0}^{T_{\mathrm{p}}}(C I-C O)(1+d)^{-t}=0 \\
T_{p}=\frac{\lg N B-\lg (N B-K v)}{\lg (1+v)} \\
N P V(d)=\sum_{t=0}^{n_{\mathrm{ES}}}(C I-C O)_{t}(1+d)^{-t}
\end{gathered}
$$

When $N P V(d) \geq 0$, the project is profitable.

\subsection{Profit Distribution Based on Electricity Retailer Contribution Degree}

Following the planning of the shared ES, the generated benefits need to be distributed among the electricity retailers. A cost allocation method based on the concept of Shapley value has been proposed. Shapley value takes the marginal individual contribution to a collective as the basis for benefit allocation. In the process, it is required to compare the cost difference between the individual optimization and collective optimization. Thus, the calculation will be very complicated when there are more individuals involved [37]. To simplify the calculation process, we propose the concept of the shared ES output ratio, and the contribution degree of a single electricity retailer 
in order to conduct the benefit allocation.

The output ratio of the shared ES is defined as the percentage of the reduced value of total electricity purchase cost compared to the ES investment cost. It can be calculated as

$$
\xi=\frac{\sum_{i=1}^{m} C_{\text {buy } 0}^{i}-\sum_{i=1}^{m} C_{\text {buy }}^{i}}{C_{\text {ess }}}
$$

The contribution degree of the electricity retailer $\mathrm{i}$ is defined as the output ratio improved due to the participation of the shared ES, which can be formulated as

$$
\delta_{i}=\frac{\xi_{+i}-\xi_{-i}}{\xi_{-i}}
$$

where $\delta_{i}$ is the contribution degree of the electricity retailer $i ; \xi_{-i}$ and $\xi_{+i}$ are the output ratios of the shared ES before and after the electricity retailer $i$ participates.

The economic benefits allocated to the electricity retailer $i$ can be expressed as:

$$
B_{i}=\delta_{i}\left(\sum_{i=1}^{m} C_{\mathrm{buy} 0}^{i}-\sum_{i=1}^{m} C_{\mathrm{buy}}^{i}-C_{\mathrm{ess}}\right)
$$

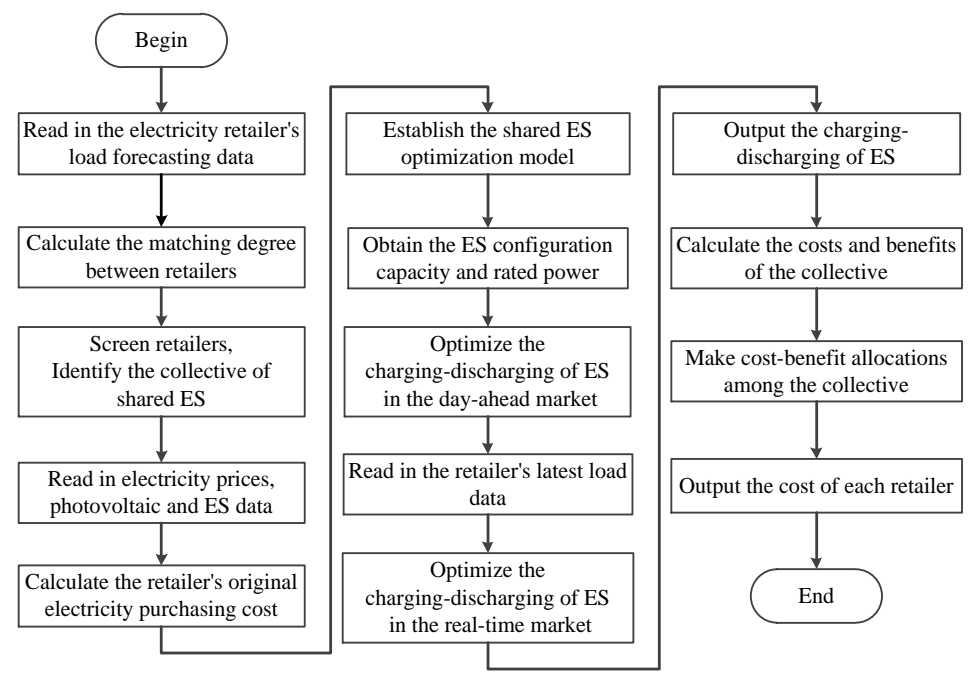

Fig. 3. The flowchart of the planning process

Overall, the planning process of this paper mainly includes three parts: the configuration of the shared ES, the optimization of the charging-discharging profile of ES, and the cost allocation among the electricity retailers, as shown in Fig. 3. 


\section{Case Study}

\subsection{Case Description}

The proposed planning scheme and benefit analysis for the shared ES are demonstrated by a case study that takes 20 electricity retailers in the same area as candidates, in which 4 of them are screened and selected based on their matching degrees to jointly plan and operate the shared ES. 24 hours are selected as the day-ahead optimization time horizon of the shared ES. Each retailer is equipped with a photovoltaic device with a capacity of $6 \mathrm{MW} \cdot \mathrm{h}$, and the rated output power is $5 \mathrm{MW}$. The average power generated by photovoltaic generation in one year is used in the calculation. The annual average data is used as the load data of electricity retailers, which is shown in Fig. A1 in Appendix. The load forecast error is represented by the normal distribution, $\mathrm{N}(8,1.42719)$. The peak periods are set at 8:00 12:00 and 17:00 21:00, the valley period is from 0:00 to 8:00 and the remaining time is the flat period [38]. The coefficients of the clearing price in the day-ahead market, $d$, and $e$, are chosen as 0.00035 and -0.231 respectively. The clearing price is depicted in Fig. A2 in the Appendix, which is the average clearing price of the electricity market that the 20 retailers participate in one year. The up-regulated and down-regulated prices in the real-time market are $¥ 800 / \mathrm{MW} \cdot \mathrm{h}$ and $¥ 600 / \mathrm{MW} \cdot \mathrm{h}$ respectively [39]. Electricity retailers have an error margin of $3 \%$, the inflation rate of $1.5 \%$, a discount rate of $9 \%$, and the benchmark yield of $10 \%$ [40].

The lithium-ion battery is chosen for the demonstration because of its superiority in safety, efficiency, and life cycle. The ES parameters are shown in Table A1 of the Appendix [41]. Electricity in the ES system at the beginning and end of the optimization periods is set as 0, and the unit electricity subsidy for ES is set as $¥ 300 / \mathrm{MW} \cdot \mathrm{h}$.

\subsection{Calculation of the Matching degree}

Two groups of retailers, respectively with high and low matching degrees, are selected for demonstration in this section. By choosing the electricity retailer 1 as the benchmark, the matching degrees between retailer 1 and other retailers are calculated in turn. The computed matching degrees at each time interval are presented in Fig. 4. The average matching degrees are shown in Table A2 of the Appendix. Among them, retailers 6/14/19 have the highest matching degrees with 
retailer 1 , with values of $0.7123 / 0.7168 / 0.7170$ respectively. Therefore, the group with high matching degrees are selected including the electricity retailers $1 / 6 / 14$ and 19 .

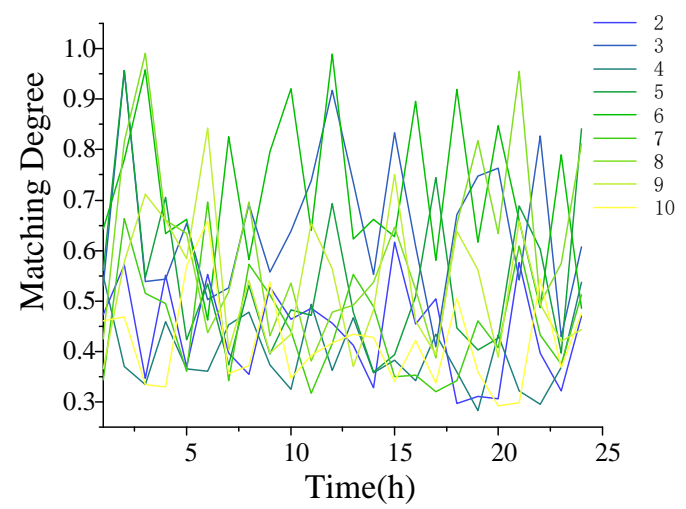

(a) Matching degree between retailer 1 and 2 10

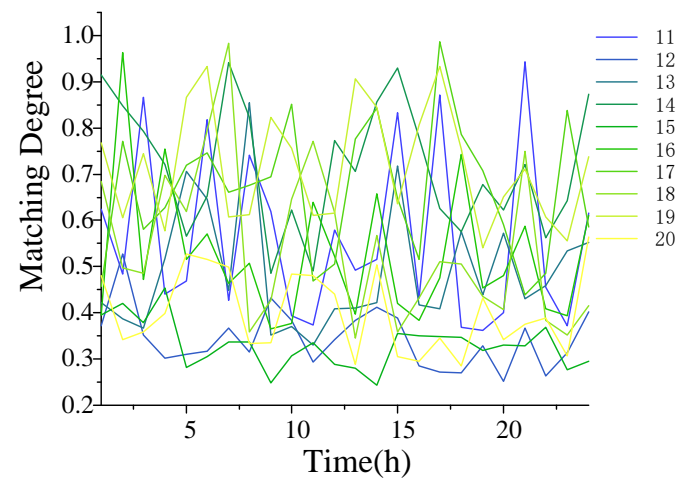

(b) Matching degree between retailer 1 and11 20

Fig.4. Matching degree between electricity retailer 1 and other electricity retailers

As given in Table A2, the matching degree between retailer 1 and retailer 15 is the lowest, with a value of 0.3300 . To ensure that each member of the collective has a low matching degree, we calculate the matching degrees between retailer 15 and the remaining 15 retailers. The results at each time are listed in Fig.A3 and the average matching degrees are shown in Table A3 of the Appendix, retailer 3 is chosen due to the lowest matching degree with retailer 15. Analogously, the matching degrees between retailer 3 and the remaining retailers are calculated, shown in Table A4 of the Appendix. Finally, the group with a low matching degree is composed of electricity retailers $1 / 3 / 12$ and 15 .

\subsection{Optimization Results of separately configured ES}

To verify the economic benefits of employing the shared ES, the planning results of the separately configured ES are computed in this section as the comparison. The optimization results 
are shown in Table 1, Table 2 presents the cost of importing electricity in the day-ahead and real-time markets of each electricity retailer without the ES. Fig. 5 outlines the annual costs including the up-regulation, down-regulation, charging, and investment cost, together with the subsidy benefits.

As indicated in Table 2, the majority of the total cost is spent on the day-ahead market. The day-ahead market purchase cost of retailer 12 accounts for the largest proportion, reaching $88.87 \%$. The electricity retailers need to participate in the real-time market at a high price to address the load forecast error. The average annual cost spends on the real-time market for the 7 retailers is 27.75 million yuan, accounting for $13.80 \%$ of the total cost.

Table 1 indicates that the largest configured capacity is required by retailer 19 with a capacity of $18.13 \mathrm{MW} \cdot \mathrm{h}$, and the initial investment is 40.11 million yuan. Electricity retailer 1 has the minimum ES capacity with $6.62 \mathrm{MW} \cdot \mathrm{h}$, and 21.59 million yuan is required for the investment. By comparing the results in Table 1 and Table 2, it is noticed that the cost of the real-time market has fallen dramatically for retailers, with an average reduction of $52.82 \%$. Fig. 5 verifies that the real-time market costs rarely account for more than $30 \%$ of all costs. Besides, the total investment and charging cost of ES account for the largest, with the proportion of more than 50\%.

Table 1 Optimization Results of Separately Configured ES

\begin{tabular}{|c|c|c|c|c|c|c|}
\hline $\begin{array}{c}\text { The serial number } \\
\text { of electricity } \\
\text { retailers }\end{array}$ & $\begin{array}{c}\text { Parameters of } \\
\text { ES } \\
(\mathrm{MW} \cdot \mathrm{h} / \mathrm{MW})\end{array}$ & $\begin{array}{c}\text { Initial } \\
\text { investment cost } \\
\left(10^{6} ¥\right)\end{array}$ & $\begin{array}{c}\text { Day-ahead } \\
\text { market } \\
\left(10^{6} ¥\right) \\
\end{array}$ & $\begin{array}{c}\text { Real-time } \\
\text { market } \\
\left(10^{6} ¥\right) \\
\end{array}$ & $\begin{array}{l}\text { The total purchase } \\
\text { cost of electricity } \\
\left(10^{6} ¥\right)\end{array}$ & $\begin{array}{c}\text { Payback } \\
\text { period } \\
\text { (year) }\end{array}$ \\
\hline 1 & $6.62 / 5.81$ & 21.59 & 172.06 & 19.93 & 195.79 & 7.80 \\
\hline 6 & $11.52 / 5.91$ & 28.24 & 170.63 & 11.64 & 190.49 & 4.57 \\
\hline 14 & $15.79 / 6.22$ & 34.63 & 172.59 & 12.45 & 194.64 & 5.22 \\
\hline 19 & $18.13 / 7.38$ & 40.11 & 171.11 & 14.78 & 199.92 & 4.27 \\
\hline 3 & $7.48 / 4.01$ & 18.72 & 170.50 & 19.16 & 196.21 & 5.47 \\
\hline 12 & $11.97 / 6.48$ & 30.09 & 171.88 & 6.51 & 187.87 & 5.71 \\
\hline 15 & $10.82 / 6.34$ & 28.28 & 180.75 & 8.01 & 198.81 & 3.78 \\
\hline
\end{tabular}

Table 2 Electricity Purchase Costs without ES

\begin{tabular}{ccccc}
\hline $\begin{array}{c}\text { The serial number of } \\
\text { electricity } \\
\text { retailers }\end{array}$ & $\begin{array}{c}\text { The peak-valley difference of } \\
\text { load(MW) }\end{array}$ & $\begin{array}{c}\text { Day-ahead } \\
\text { market } \\
\left(10^{6} ¥\right)\end{array}$ & $\begin{array}{c}\text { Real-time } \\
\text { market } \\
\left(10^{6} ¥\right)\end{array}$ & $\begin{array}{c}\text { The total purchase cost of } \\
\text { electricity } \\
\left(10^{6} ¥\right)\end{array}$ \\
\hline 1 & 14.92 & 171.10 & 27.46 & 198.56 \\
6 & 15.68 & 168.89 & 27.77 & 196.67 \\
14 & 20.37 & 172.13 & 29.14 & 201.28 \\
19 & 18.67 & 174.55 & 34.77 & 209.32 \\
12 & 19.03 & 172.05 & 27.58 & 199.63 \\
15 & 22.03 & 171.64 & 21.50 & 193.14 \\
\end{tabular}




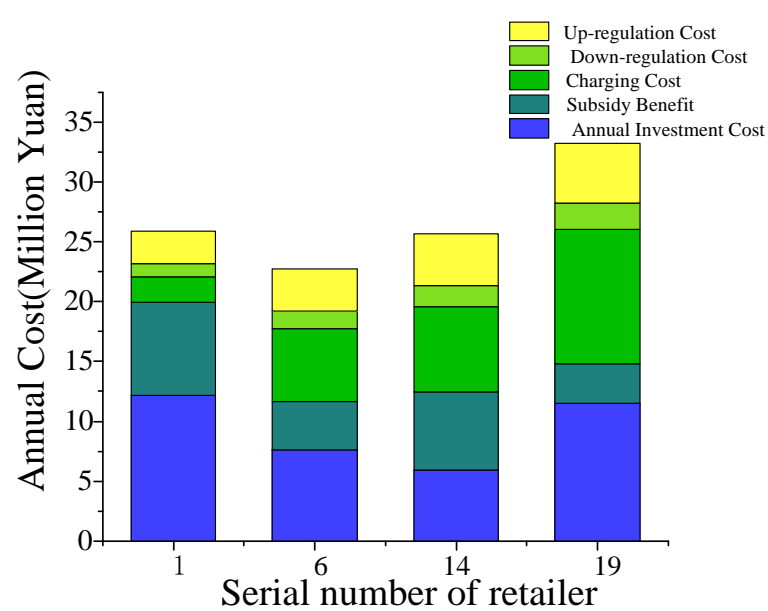

Fig. 5. Various costs of electricity retailers after ES installed

On the contrary, the day-ahead market cost does not change significantly after the installation of ES. The reason is that the charging-discharging capacity of ES is limited, and the electricity price in the real-time market is significantly higher than that in the day-ahead market. Therefore, ES mainly participates in the real-time market and the impact on the power purchase cost in the day-ahead market is not significant. On the whole, after installing the ES, the electricity purchase cost decreases by $2.91 \%$ on average, and the ES investment can be recovered within its life cycle, with an average payback period of 5.26 years.

\subsection{Optimization Results of shared ES for high-matching group}

The above results have proved that the ES can effectively reduce the purchase cost of electricity retailers. However, the initial investment cost is relatively high, which accounts for $11.59 \%$ of the total annual cost of retailers on average. The high investment cost generates great economic pressure on retailers, which is limiting the development and application of the ES. To necessitate the ES to become a more affordable and profitable option, the analysis of the optimization on shared ES is conducted.

For the group of retailers identified with a high matching degree, the optimal planned capacity of the shared ES is $22.04 \mathrm{MW} \cdot \mathrm{h}$ with the initial investment cost of 49.18 million yuan. The actual operating life of the ES is 13.39 years. After the benefit distribution among the collective, the costs and benefits of each electricity retailer are detailed in Table 3 . The electricity of each retailer purchased in the real-time market is illustrated in Fig. 6.

Table 3 Optimization Results of Shared ES for High Matching Degree Group 


\begin{tabular}{cccccc}
\hline $\begin{array}{c}\text { Retailer } \\
\#\end{array}$ & $\begin{array}{c}\text { Initial investment } \\
\text { cost } \\
\left(10^{6} ¥\right)\end{array}$ & $\begin{array}{c}\text { Day-ahead market } \\
\text { cost } \\
\left(10^{6} ¥\right)\end{array}$ & $\begin{array}{c}\text { Real-time market } \\
\text { cost } \\
\left(10^{6} ¥\right)\end{array}$ & $\begin{array}{c}\text { Annual electricity } \\
\text { purchase } \\
\text { cost(106) }\end{array}$ & $\begin{array}{c}\text { Percentage of cost } \\
\text { reduction }\end{array}$ \\
\hline 1 & 8.52 & 173.30 & 8.85 & 184.17 & $7.24 \%$ \\
6 & 11.14 & 171.85 & 5.28 & 179.18 & $8.89 \%$ \\
14 & 13.67 & 173.83 & 5.16 & 183.09 & $9.03 \%$ \\
19 & 15.83 & 172.34 & 7.12 & 188.05 & $10.16 \%$ \\
\hline
\end{tabular}

As shown in Table 3, the investment costs on the shared ES required by the retailers are greatly reduced with an average reduction of $60.52 \%$, compared with the case of individually investing the ES for each retailer. Moreover, the recycling cycle is shortened from 5.26 years to 3.75 years on average. The meaning of operating ES is still to reduce the cost of the real-time market significantly. For retailer 1, the annual cost in the real-time market is reduced from 27.46 million yuan to 8.85 million yuan under the sharing mode. Fig. 6 suggests that the electricity purchased in the real-time market can be effectively reduced by the installation of the ES. And a further decrease of energy trading in the real-time market can be observed when the shared ES is operated.

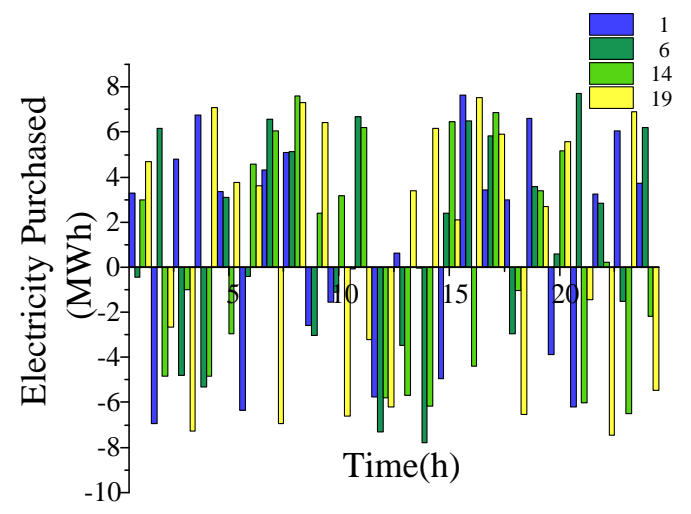

(a) Electricity purchased in real-time market before ES installed

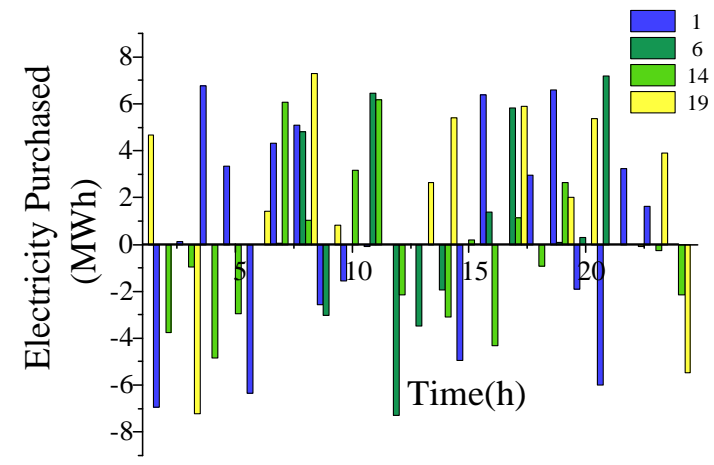

(b) Electricity purchased in real-time market after ES installed separately 


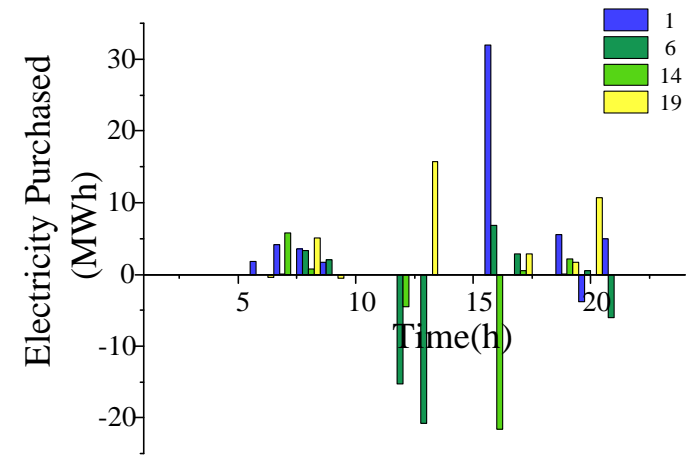

(c) Electricity purchased in real-time market after shared ES installed

Fig. 6. Electricity purchased in the real-time market

The annual electricity procurement cost of retailer 1 decreases by $1.39 \%$ when the ES is independently planned for each retailer, while the proportion grows to $7.24 \%$ with the installation of the shared ES. The average cost of purchasing electricity falls by $8.83 \%$. In conclusion, the retailers invested on the shared ES could benefit from a lower investment, a higher economic profit, and a shorter payback period.

\subsection{Optimization Results of shared ES for low matching degree group}

The set of electricity retailers with low matching degrees has been identified in Section 6.2, consisting of retailers $1 / 3 / 12 / 15$. This section analyzes the economic benefits of the shared ES for retailers with a low matching degree and compares the results with the optimization results in Section 6.4.

For the retailer group with a low matching degree, the optimal configured capacity of the shared ES is derived as $16.48 \mathrm{MW} \cdot \mathrm{h}$ with a payback period of 9.69 years. The actual operating life of the ES is 11.02 years. Each specific cost of all retailers is shown in Table 4.

Table 4 Optimization Results of Shared ES for Low Matching Degree Group

\begin{tabular}{cccccc}
\hline $\begin{array}{c}\text { Retailer } \\
\#\end{array}$ & $\begin{array}{c}\text { Initial investment } \\
\text { cost } \\
\left(10^{6} ¥\right)\end{array}$ & $\begin{array}{c}\text { Day-ahead market } \\
\text { cost } \\
\left(10^{6} ¥\right)\end{array}$ & $\begin{array}{c}\text { Real-time market } \\
\text { cost } \\
\left(10^{6} ¥\right)\end{array}$ & $\begin{array}{c}\text { Annual electricity } \\
\text { purchase } \\
\text { cost }\left(10^{6} ¥\right)\end{array}$ & $\begin{array}{c}\text { Percentage of cost } \\
\text { reduction }\end{array}$ \\
\hline 1 & 12.28 & 171.81 & 9.42 & 184.41 & $7.12 \%$ \\
3 & 12.30 & 170.25 & 8.65 & 184.81 & $7.42 \%$ \\
12 & 11.78 & 171.63 & 3.26 & 176.95 & $8.38 \%$ \\
15 & 12.47 & 180.48 & 3.43 & 187.26 & $9.22 \%$ \\
\hline
\end{tabular}

By comparing Table 1 and Table 4, it can be seen that the annual costs of the retailers in the collective with low matching degree decrease because of the employment of the shared ES. For retailer 3, the annual purchase cost decreases from 196.21 million yuan to 184.81 million yuan, with a decrease rate of $5.81 \%$. It represents a larger saving of cost compared with the case of 
independently planning the ES, whose decrease rate is $3.62 \%$. Additionally, the main advantage of using the shared ES, which is to reduce user's investment cost, is also validated for the group of retailers with a low matching degree. The investment cost required by retailer 12 is 30.09 million yuan when ES is configured separately, while only 11.78 million yuan is needed to invest the shared ES. However, for the group of retailers with a low matching degree, the recovery cycle of the shared ES is longer than that of users independently configuring the ES. In terms of the retailer 12, the investment cost can be paid back after 3.78 years under the case that the ES is independently planned, while requires 9.69 years for the shared ES.

The economic performances of the respective shared ES for the groups of high and low matching degrees are compared and analyzed as follows.

As shown in Table 3 and Table 4, although both the investment on the ES can be effectively reduced for the two groups of retailers, the proportion of investment cost reduction is higher for the group with a high matching degree, with an average decrease of $60.52 \%$, while it is $48.55 \%$ for the group with low matching degree. Additionally, compared with the low-matched group, the proportion of the power purchase cost decreases by $7.95 \%$ for the high-matched group. The optimization for the two groups of retailers has performed almost the same effect on reducing the real-time market purchase cost, with an average reduction of $77.64 \%$ and $76.50 \%$ respectively.

The optimized charging and discharging power of the shared ES and average deviation of load forecasting for the two groups of retailers are shown in Fig. 7.

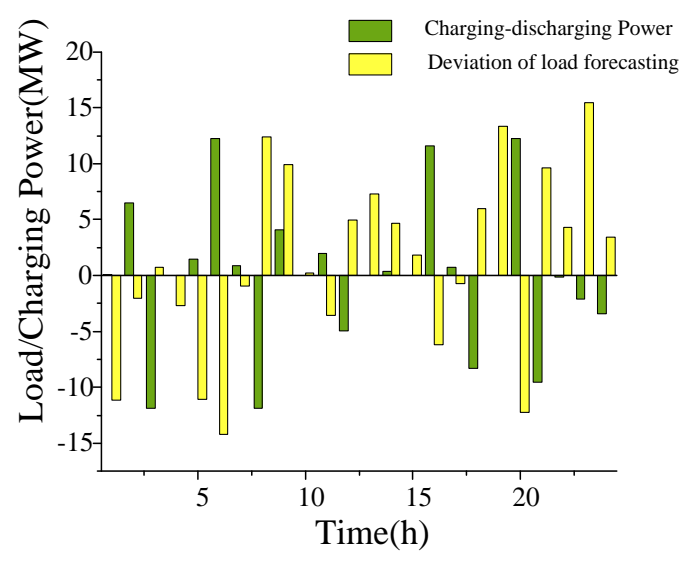

(a) Charging-discharging of ES for high-matching group 


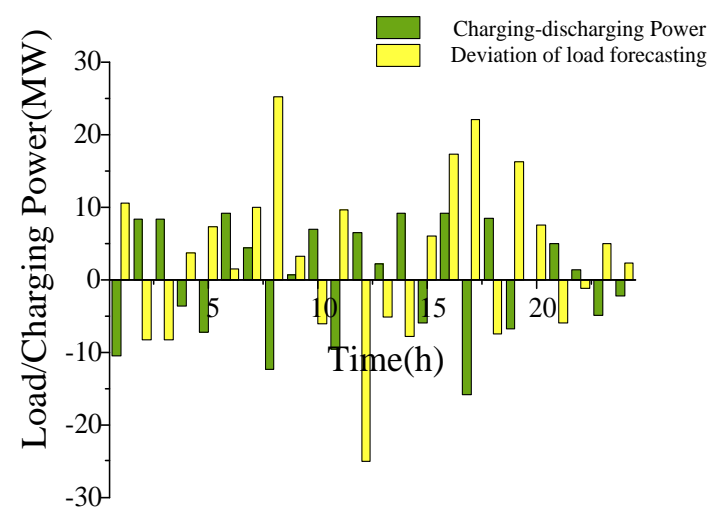

(b) Charging-discharging of ES for low-matching group

Fig. 7. Charging-discharging power of shared ES

Fig. 7 indicates that the shared ES's charging and discharging actions are mainly activated to fulfill the load prediction deviation. The power deviation can be satisfied as far as possible by the ES, to reduce the power purchased in the real-time market. However, when the retailer's matching degree is high, the frequency of charging-discharging is lower, but the charging-discharging power is larger because they have similar charging-discharging demands. On the contrary, for retailers with a low matching degree, the ES needs frequent charging and discharging to meet the demand of each retailer, resulting in a rapid capacity fading for the ES. It proves that the shared ES for retailers with a low matching degree has a shorter operating life.

In conclusion, compared with the case that the ES configured separately for each retailer, planning and operating the ES in a shared manner can improve the economic benefits and reduce the investment cost, which is conducive to the commercial development of ES. However, when the matching degree among retailers is low, the recovery cycle of the shared ES is longer, hence affects the overall profits of using the ES. Although the selection of retailers with a high matching degree to form a shared collective may result in a more concentrated peak and valley difference of load, the economic benefit of the shared ES is still better.

\section{Conclusion}

A method of optimal planning and investment benefit analysis of ES shared by multiple electricity retailers is proposed in this paper, in which a concept of matching degree to screen retailers for greater economic benefit is introduced. The optimization objective is defined as minimizing the electricity procurement cost of the electricity retailer. The retailers can be 
classified with a low or high matching degree based on the theory of curve correlation degree. The optimal planning model of the shared ES is established and the investment benefit analysis is carried out in detail. The case study is investigated to compare the profits of the two groups of retailers in jointly planning and operating the ES. The specific conclusions are as follows:

(1) ES can significantly reduce the cost of purchasing electricity in the real-time market. The annual electricity purchase costs of retailers drop by $2.91 \%$ on average after the installation of independently configured ES for each retailer, and the investment can be recovered in 5.26 years as estimated in the case study.

(2) The advantages of employing the shared ES can be amplified after screening multiple retailers based on the matching degree. For the group of retailers with a high matching degree, the investment cost required by each electricity retailer decreases by $60.52 \%$ on average, and the payback period is shortened to 3.75 years. Moreover, compared to the case that each retailer independently planning its own ES, the percentage of electricity purchase cost reduction increases from $2.91 \%$ to $8.83 \%$.

(3) When the matching degree of the collective of retailers is low, compared to separately configure the ES for each retailer, the shared ES can still effectively reduce the investment cost and improve the economic benefit. Specifically, the electricity purchase costs of retailers are reduced by $8.03 \%$ on average. However, frequent charging and discharging will affect the actual operating life of the ES, and the recovery cycle is also the longest among all planning cases, reaching 9.69 years.

\section{Acknowledgment}

This work was supported by the China Electric Power Research Institute (SGDK0000PDJS1901223), the Young Elite Scientists Sponsorship Program of Chinese Society of Electrical Engineering(CSEE-YESS-2018006) and the National Natural Science Foundation of China (51807127).

\section{Appendix}

Table A1 Parameter of Energy Storage

\begin{tabular}{cccc}
\hline CPINV & CEINV & COP & \\
$(¥ /$ & $(¥ /$ & $(¥ /$ & $\eta_{c}$ \\
$\mathrm{KW} \cdot \mathrm{H})$ & $\mathrm{KW})$ & $\mathrm{KW} \cdot \mathrm{A})$ & \\
\hline
\end{tabular}




\begin{tabular}{cccc}
\hline 2234 & 1173 & 97 & 0.9 \\
\hline$\eta_{\mathrm{dis}}$ & TMAX & SPECIFIC ENERGY \\
$(\mathrm{WH} / \mathrm{KG})$ & 210 & $\begin{array}{c}\text { SPECIFIC POWER } \\
(\mathrm{W} / \mathrm{KG})\end{array}$ \\
\hline 0.9 & 15 & 270 & 270 \\
\hline
\end{tabular}

Table A2 Matching Degree between Retailer1 and Other Retailers

\begin{tabular}{|c|c|c|c|c|c|c|}
\hline $1-2$ & $1-3$ & $1-4$ & $1-5$ & $1-6$ & $1-7$ & $1-8$ \\
\hline 0.4395 & 0.6469 & 0.3963 & 0.5402 & 0.7123 & 0.4534 & 0.6055 \\
\hline $1-9$ & $1-10$ & $1-11$ & $1-12$ & $1-13$ & $1-14$ & $1-15$ \\
\hline 0.5334 & 0.4189 & 0.5623 & 0.3434 & 0.4894 & 0.7168 & 0.3300 \\
\hline $1-16$ & & $1-17$ & $1-18$ & & & $1-20$ \\
\hline 0.5230 & & 0.6650 & 0.5433 & & & 0.4008 \\
\hline
\end{tabular}

Table A3 Matching Degree between Retailer15 and Other Retailers

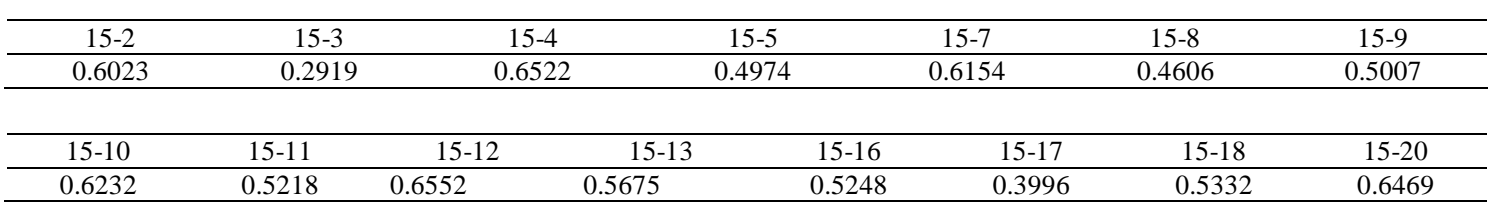

Table A4 Matching Degree between Retailer3 and Other Retailers

\begin{tabular}{cccccccc}
\hline $3-2$ & $3-4$ & $3-5$ & $3-7$ & $3-8$ & $3-9$ & $3-10$ \\
\hline 0.3697 & 0.3439 & 0.4487 & 0.3773 & 0.5069 & 0.4628 & \\
\hline & & & & & & \\
\hline $3-11$ & $3-12$ & $3-13$ & $3-16$ & $3-17$ & $3-18$ & $3-20$ \\
\hline 0.4409 & 0.2989 & 0.4231 & 0.4548 & 0.5758 & 0.4522 & 0.3494 \\
\hline
\end{tabular}

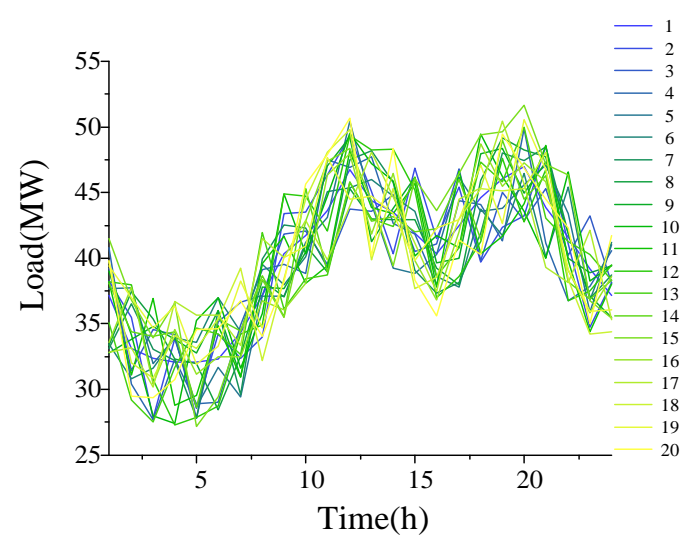

Fig.A1. Load of electricity retailers

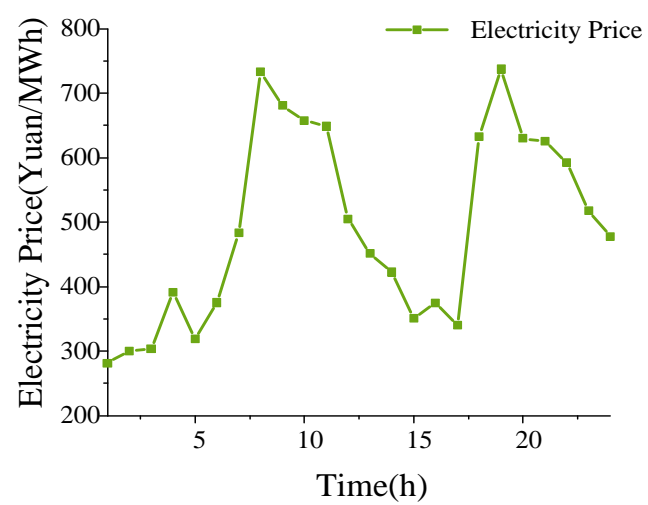

Fig.A2. Clearing price in the day-ahead market 


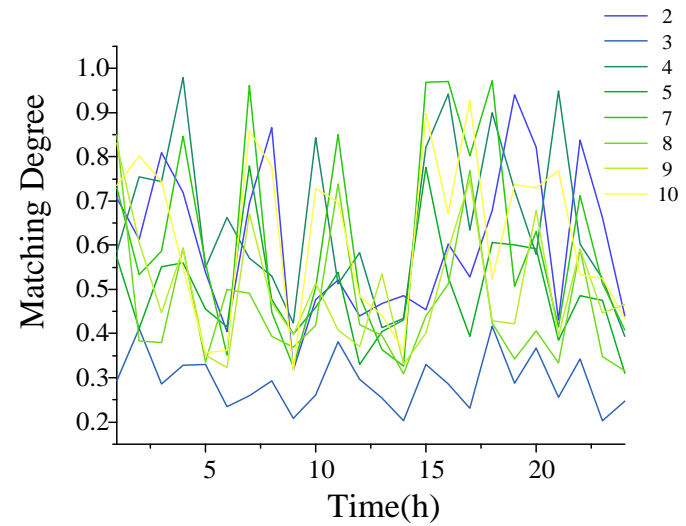

(a) Matching degree between retailer 15 and 2 10

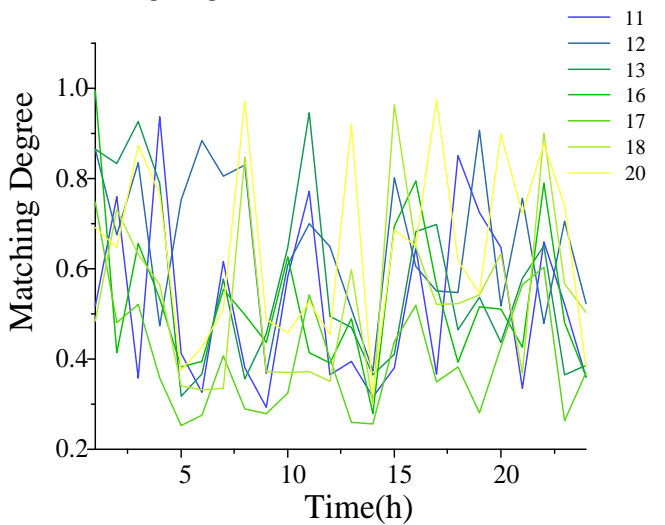

(b) Matching degree between retailer 15 and11 20

Fig.A3. Matching degree between electricity retailer 15 and other electricity retailers

\section{References}

[1] X.Fang, et al. "Mean-Variance Optimization-Based Energy Storage Scheduling Considering Day-Ahead and Real-Time LMP Uncertainties.” IEEE Transactions on Power Systems, vol.33, no.6, pp.7292-7295, Nov. 2018.

[2] K.Bruninx, et al. "Coupling Pumped Hydro Energy Storage With Unit Commitment." IEEE Transactions on Sustainable Energy, vol.7, no.2, pp.786-796, Apr. 2016.

[3] Z.Z. Yuan Z, Z.Yun, H.Qi, et al. "Market-oriented optimal dispatching strategy for a wind farm with a multiple stage hybrid energy storage system." CSEE Journal of Power and Energy Systems, vol. 4, no. 4, pp.417-424, Dec. 2018.

[4] G.Lorenzi, C.A.S.Silva. "Comparing demand response and battery storage to optimize self-consumption in PV systems." Applied Energy, vol.180, no.15, pp.524-535, Oct. 2016.

[5] N.I.Nwulu, X.H.Xia. "Optimal dispatch for a microgrid incorporating renewables and demand response." Renewable Energy, vol.101, pp.16-28, Feb. 2017.

[6] P.C.D.Granado, Z.Pang, S.W.Wallace. "Synergy of smart grids and hybrid distributed generation on the value of energy storage." Applied Energy, vol.170, no.15, pp.476-488, May. 2016.

[7] M.Nazari-Heris, et al. "Economic-environmental effect of power to gas technology in coupled electricity and gas systems with price-responsive shiftable loads." Journal of Cleaner Production, vol.244, 118769, Jan. 2020.

[8] M.T.Lawder , et al. "Battery Energy Storage System (BESS) and Battery Management System (BMS) for Grid-Scale Application.” Proceedings of the IEEE, vol.102, no.6, pp.1014-1030, Jun. 2014. 
[9] Y.Y. Shi, et al. "Using battery storage for peak shaving and frequency regulation: Joint optimization for superlinear gains." IEEE Transactions on Power Systems, vol.33, no.3, pp.2882-2894, Aug. 2018.

[10] M.Nick, R.Cherkaoui, M.Paolone. "Optimal allocation of dispersed energy storage systems in active distribution networks for energy balance and grid support.” IEEE Transactions on Power Systems, vol.29, no.5, pp.2300-2310, Sept. 2014.

[11] X.Q.Zhu, J.H.Yan, N.Lu. “A graphical performance-based energy storage capacity sizing method for high solar penetration residential feeders.” IEEE Transactions on Smart Grid, vol.8, no.1, pp.3-12, Jan. 2016.

[12] H. Mostafa H, Mostafaa, H.E. Shady, et al. “Techno-economic assessment of energy storage systems using annualized life cycle cost of storage (LCCOS) and levelized cost of energy (LCOE) metrics. " Journal of Energy Storage, vol.29, Jun. 2020

[13] K.K. Mark, E.L. Mohammed, B.A.Oludamilare, et al. "Integrated approach for optimal techno-economic planning for high renewable energy-based isolated microgrid considering cost of energy storage and demand response strategies." Energy Conversion and Management, vol.215, Jul.2020.

[14] H. B.Yamchia, H. Shahsavaria, N. T. Kalantari, et al. "A cost-efficient application of different battery energy storage technologies in microgrids considering load uncertainty.” Journal of Energy Storage, vol.22, pp.17-26, Apr.2019.

[15] Energy Trend. "NEC releases household power storage system," [Online]. Available: http://www.energytrend.com/node/3319. 2012.

[16] D.Kalathil, et al. "The sharing economy for the electricity storage." IEEE Transactions on Smart Grid, vol.10, no.1, pp.556-567, Jan. 2019.

[17] P.Chakraborty, et al. "Sharing storage in a smart grid: A coalitional game approach." IEEE Transactions on Smart Grid, vol.10, no.4, pp.4379-4390, Jul. 2019.

[18] P.Lombardi, F.Schwabe. "Sharing economy as a new business model for energy storage systems." Applied Energy, vol.188, pp.485-496, Feb. 2017.

[19] K. Kusakana. "optimal peer-to-peer energy management between grid-connected prosumers with battery storage and photovoltaic systems.” Journal of Energy Storage, vol.32, Dec. 2020.

[20] Z.M.Wang, et al. "Active demand response using shared energy storage for household energy management." IEEE Transactions on Smart Grid, vol.4, no.4, pp.1888-1897, Dec. 2013.

[21] Z.M.Wang, C.H.Gu, F.R.Li. "Flexible operation of shared energy storage at households to facilitate PV penetration." Renewable Energy, vol.116, part A, pp.438-446, Feb. 2018

[22] A.Downward, D.Young, G.Zakeri. "Electricity retail contracting under risk-aversion." European Journal of Operational Research, vol.251, no.3, pp.846-859, Jun. 2016.

[23] M. B. Roberts, A. Bruce, I. MacGilla. "Impact of shared battery energy storage systems on photovoltaic self-consumption and electricity bills in apartment buildings.” Applied Energy, vol.245, pp.78-95, Jul. 2019.

[24] F.Hafiza, A.R. de Queirozb, P.Fajri. "Energy management and optimal storage sizing for a shared community: A multi-stage stochastic programming approach.” Applied Energy, vol.236, pp.42-54, Feb. 2019.

[25] A.Taşckkaraoğlu. "Economic and operational benefits of energy storage sharing for a neighborhood of prosumers in a dynamic pricing environment.” Sustainable Cities and Society, vol.38, pp.219-229, Apr. 2018.

[26] T.AlSkaif a, A.C. Luna, M.G. Zapataa, et al. "Reputation-based joint scheduling of households appliances and storage in a microgrid with a shared battery.” Energy and Buildings, vol.138, pp.228-239, Mar. 2017. 
[27] A.Downward, D.Young, G.Zakeri. "Electricity retail contracting under risk-aversion.” European Journal of Operational Research, vol.251, no.3, pp.846-859, Jun. 2016.

[28] R.Q.Wang, Y.Z.Li. "Load shedding strategies of power supplier considering impact of interruptible loads on spot price." Power System Technology, vol.33, no.18, pp.111-116, Oct. 2009.

[29] Y.X.Chai, et al. "Incentive-based demand response model for maximizing benefits of electricity retailers." Journal of Modern Power Systems and Clean Energy, vol.7, no.6, pp.1644-1650, Nov. 2019.

[30] V.A.Evangelopoulos, P.S.Georgilaki. "Optimal distributed generation placement under uncertainties based on point estimate method embedded genetic algorithm.” Transmission and Distribution, vol.8, no.3, pp.389-400, Mar.2014.

[31] Y.F.Yang, J.C.Liu. "Two-stage decision-making method for power sales companies considering power mutual protection strategy.” Automation of Electric Power Systems, vol.41, no.24, pp.126-134, Nov. 2017.

[32] Y.P. Xiang, Z.N. Wei, G.Q.Sun, et al. "Life cycle cost based optimal configuration of battery energy storage system in distribution network.” Power System Technology, vol.39, no.1, pp.264-270, Jan. 2015.

[33] J.F.Manwell, et al. “ Hybrid2-a hybrid system simulation model-theory manual.” Renewable Energy Research Laboratory, University of Massachusetts. 2006.

[34] Y.G.Gui, L.D.Yuan, L.J. Hui , et al. "A cost accounting method of the Li-ionbattery energy storage system forfrequency regulation considering the effect of life degradation." Protection and Control of Modern Power Systems, vol.1, pp.43-51, Mar.2018.

[35] D.U.Sauer, H. Wenzl. “Comparison of different approaches for lifetime prediction of electrochemical systems-using lead acid batteries as example." Journal of Power Sources, vol.176, no.2, pp.477-483, Mar.2008.

[36] S.H.Lv. "Study on economic evaluation and policy of distributed PV-energy storage system". Tianjin University. Nov. 2014.

[37] S.Q.Tang, et al. "Wireless Coordination Control of Multi-functional Grid-tied Inverters in Microgrid." Automation Electric Power Systems, vol.39, no.9, pp.200-207, May. 2015.

[38] Y.X.Ding, et al. "Optimal configuration of user-side energy storage considering power demand management." Power System Technology, vol.43, no.4, pp.1179-1186, Apr. 2019.

[39] Y.F.Yang, J.C.Liu. "Two-stage decision-making method of retailers Considering power transfer strategy," Automation of Electric Power Systems, vol.42, no.24, pp.120-128, Nov. 2017.

[40] W.Thang, et al. "A novel model to determine optimizing power and capacity for energy storage systems on competitive electricity market," IEEE Ninth International Conference on Power Electronics and Drive Systems, pp. 322-328, 2011.

[41]Y.P.Xiang, et al. "Life cycle cost based optimal configuration of battery energy storage system in distribution network," Power System Technology, vol.39, no.1, pp.264-270, Jan. 2015. 